\title{
The Sustainable Development of Smart Cities: A Case Study of the Design of driverless bus stops in Zhengzhou
}

\author{
Xiaoguang Chen ${ }^{1}$, Jinting Sui ${ }^{1, *}$, Xufeng Tai ${ }^{1}$, and Heqi $\mathrm{Li}^{1}$ \\ ${ }^{1}$ Institute of Fourth, China Northeast Architectural Design \& Research Institute Co., Ltd., Shenyang 110168, China
}

\begin{abstract}
With the arrival of the "5G" era and the digital economy era, the development of the city has permeated all aspects of the city, and with the emergence of "smart city", it is likely to have "smart" everywhere in the future city. At the same time, "Future Smart Transportation" was proposed as a discussion topic at the "2019 (8th) International Smart City Summit and Smart Ecology Expo". The research and development of the driverless bus stops will spur the driverless bus stops to take on the past with a brand-new look, welcome the future, and contribute to the sustainable development of the smart city. Taking the driverless bus station in Zhengdong New District as an example, this paper explores the sustainable development of a smart city through the creation of manned (open)-shared (transition space)-driverless (semi-enclosed space) space and the introduction of modular design approach. To connect people's work, life and transportation, and derive a new public transportation environment based on manned bus stops, namely, intelligence, sustainability, environmental friendliness and safety, thus create a smart transportation pilot to embrace the bright future of sustainable smart cities.
\end{abstract}

\section{Background}

The project is located in Zhengdong New District of Zhengzhou City (Figure 1), which adheres to the concept of green and sustainable development and strives to become an international regional financial center as well as an ecologically livable city up to international standard. Longhu Central Road is the most important urban trunk road in longhu district, where relying on the road shape and important traffic functions throughout the region and in combination with the fast-developing unmanned technology, it will be built as an unmanned experimental demonstration area. On this basis, relevant ancillary facilities along the road will be improved, and efforts will be made to build a comprehensive intelligent road.

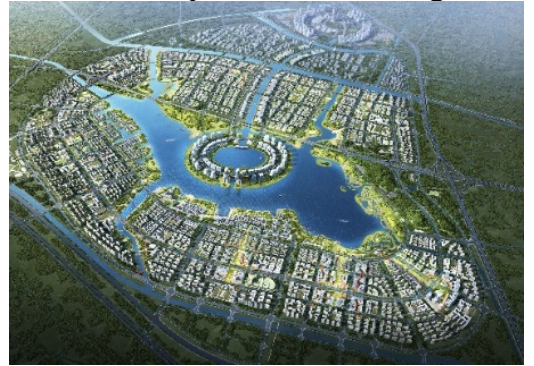

Figure 1. Aerial view of Zhengdong New District.

The project currently includes 35 general bus stops (Figure 2), with completed platforms but no bus shelters yet and some of the manned buses are in operation. The government decided to build an unmanned bus stop base on this situation. Questions are: First, how to make use of the existing platform without dismantling and damaging it using sustainable development design method. Secondly, how to guarantee the normal operation of the manned bus stops before the driverless bus stops are completed and put into use, and the solve problem of functional transformation and transition between the two in the future.

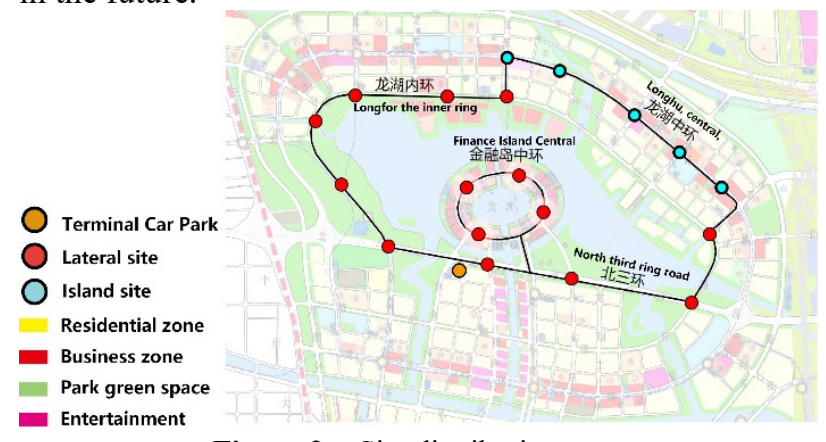

Figure 2. Site distribution map.

Based on the analysis of the site status, there are three types according to different road conditions (Figure 3 ).

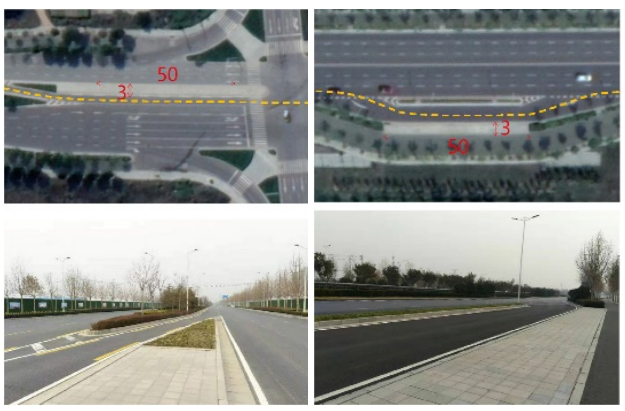

Figure 3. Island platform (left) and side platform (right).

\footnotetext{
*Corresponding author: 1402874257@qq.com
} 


\section{Architectural design}

Considering the present situation of bus stops at the beginning of the design (Figure 4), three problems are summarized: First, the functional connotation of urban bus stops is simple, which can only provide functions such as stops, seats, maps and so on. Second, the space is simple with structures that consists of columns and ceilings, which are completely open and disordered thus cannot form an effective crowd organization. Third, one-time investment leads to a short service life and no reserve conditions for upgrading. To sum up, the existing bus stations can no longer meet the future multi-functional needs, and there is no possibility of upgrading. The existing spatial structure conditions cannot effectively dock self-driving buses.
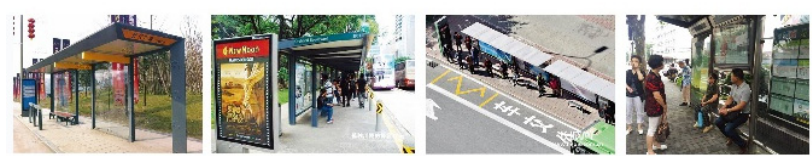

Figure 4. Present situation map of bus station.

\subsection{Sustainable development strategy}

By studying the unmanned bus and its carrying stations, the unmanned public transport platform is considered as the carrier to meet the current and future public transport system. In the practical stage, it should have the ability to adapt to the changes of the present and the future. Through one-time investment in the construction, it should meet the functional requirements of the manned bus station at the present stage, and meet the requirements of the unmanned bus station through upgrading and transformation in the future. In this way, it is possible to avoid dismantling the bus station on duty, but upgrade it in the future to cope with the era of popularization of unmanned driving, thus saving a lot of social resources, investment and time cost. This is the design of sustainable development.

\subsection{Platform space strategy}

The project itself takes into account the coexistence of the present manned and the future unmanned. We put forward the concept of manned (open) - shared (transitional space) - unmanned (semi-closed space), which makes the current manned bus platform a transition from the traditional platform to unmanned platform (Figure 5). At the same time, a shared space is added between manned and unmanned driving, which is used as a transitional space to effectively connect these three parts. And through later modularity, it can be combined freely according to functions and requirements [1-2].

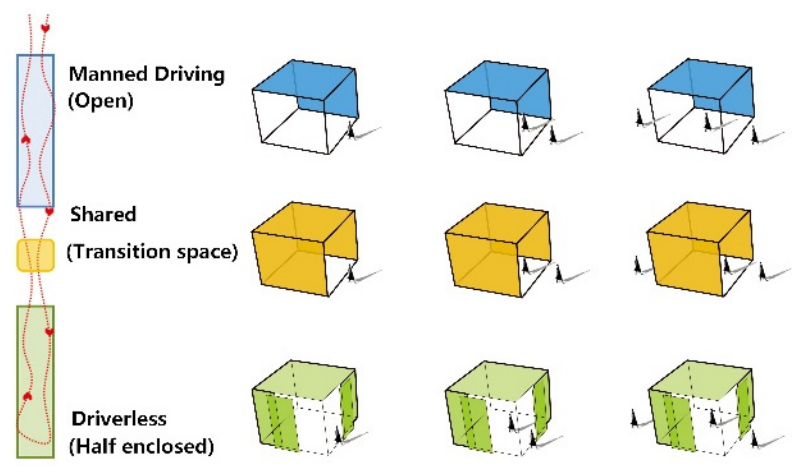

Figure 5. Schematic diagram of platform space.

\section{Modularization}

\subsection{Constructional modularization}

As a sustainable design and production method, the modularization strategy can achieve rapid construction, in line with the development of smart cities. While the idea of integrating multiple functions and demands by means of splitting and combining in the design embodies the concept of sustainability.

Inspired by the space station (Figure 6), the design takes a "space capsule" as the basic module unit for unit connection, which can realize the growth from small to large and from simple to complex, thus realizing the growth transition and transformation from manned station (with simple requirements) to driverless station (with diverse requirements).
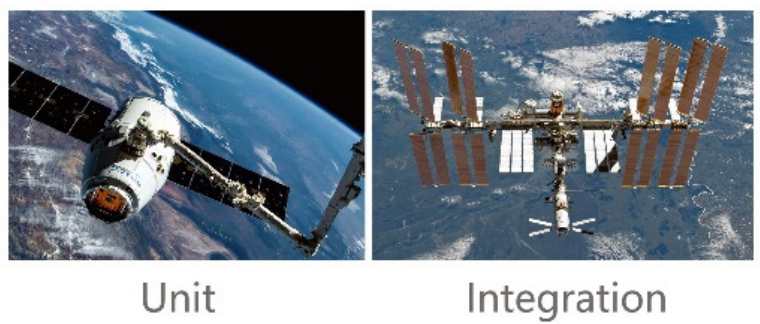

Figure 6. Image of space station.

In the design of the "space capsule" (Figure 7), the module is divided into five plate-type modules and two structural modules by adopting the modular design concept (Figure 8), wherein the five plate-type modules are maintenance modules. The basic combination is an external decorative panel plus a plate supporting structure system, in which the former can be arbitrarily switched among solar panels, electronic screens, perforated aluminum plates and toughened glass, so as to realize different functional requirements of the station.

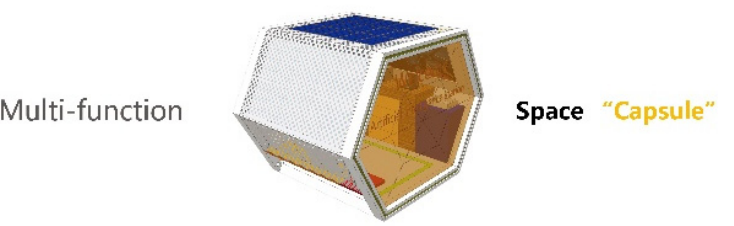

Figure 7. Structure of one capsule. 


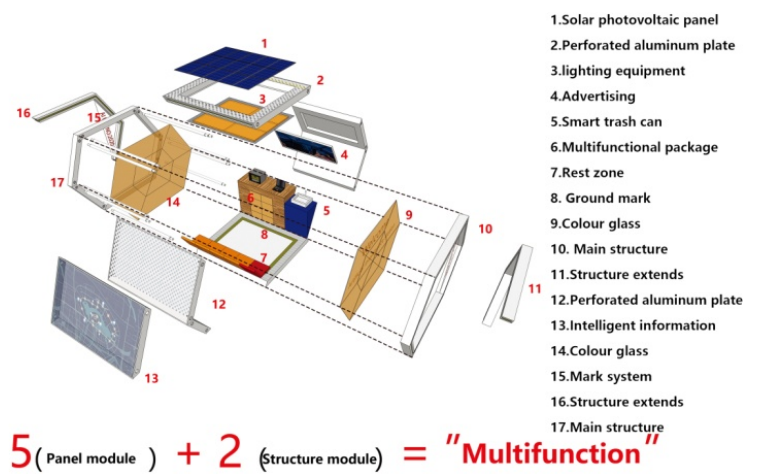

Figure 8. Explosive view of one capsule.

The structural modules on both sides are hexagonal or C-shaped structural support modules, which are welded and formed by fixed-length box steel beams in the factory and transported to the site for assembly and connection with the plate modules (Figure 9). The production mode of modular construction introduces factory prefabrication production into the construction process. Through factory prefabrication, the site construction time and difficulty are greatly reduced, while the construction efficiency is improved. Meanwhile, the modular construction strategy can effectively improve the building quality. In case of partial damage, the module can be replaced separately, thus prolonging the service life of the building, which is of sustainable development significance [3].

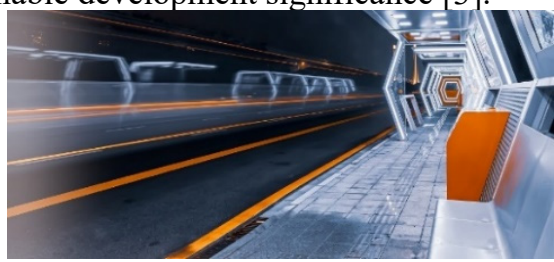

Figure 9. Real scene of stations ${ }^{1}$.

\subsection{Functional modularization}

Building modularity is connected with function modularity. Function is the basic attribute of the building itself. Therefore, in the modular building, functional zoning is mostly used as the main basis of modular divisions. The sustainable meaning of using functionbased modular division lies in that a specific module can correspond to a specific function. After summarizing and analyzing the functions of future unmanned bus stations, eight basic functional modules are designed (Figure 10), including multifunctional modules, intelligent modules and barrier-free modules[4].

\section{Flexible}

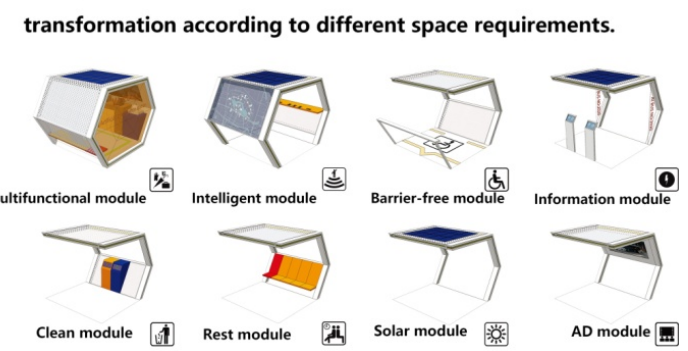

Figure 10. Diagram of one unit module.
On the basis of basic modules, different module is spliced and combined, and then auxiliary equipment is integrated to realize different combinations of multifunctional modules, including advertisement module, cleaning module, barrier-free module, electronic information module, intelligent module, etc. These modules can be flexibly combined according to different fields and requirements, and can be quickly produced and installed (Figure 11). Figures 1, 2 and 3 are relatively simple bus stops, including basic bus modules such as rest module, cleaning module and barrier-free module, which are suitable for existing platforms. 4, 5 and 6 have added solar modules, safety modules and multi-functional modules, which are suitable for the needs of smart city. 7 and 8 are the most complex ones, adding intelligent modules and shell modules to meet the needs of unmanned driving. On this basis, we can realize the transition from simple function to complex function, and upgrade from manned stations to unmanned stations, so as to meet the current needs and foreseeing the future.
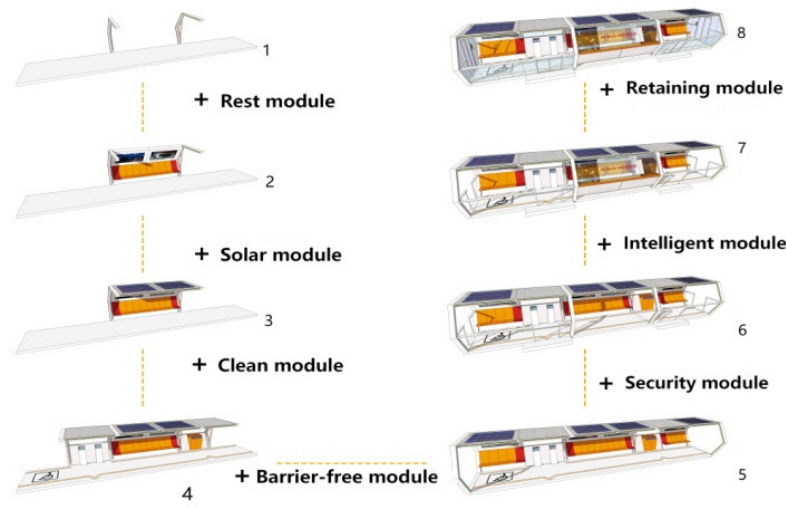

Figure 11. Growth of a bus stop.

\section{Intelligent Network: Connection of Intelligent Technology}

The new unmanned bus station is guided by the unmanned bus station and passengers' demand by introducing intelligent technology. Through the research of related new technologies, it connects people, people and cities, and matches the most advanced and suitable technology with the unmanned bus stations, providing passengers with a brand-new bus environment (Figure 12), so that every citizen can feel the coming of smart city in advance through infrastructure [5].

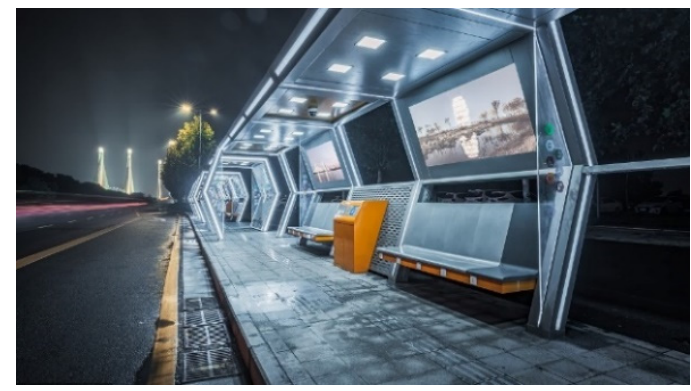

Figure 12. Real scene of stations ${ }^{1}$.

\footnotetext{
1 Source: https://www.veg.com/
} 
- Urban network: micro 5G base station, providing urban WIFI hot spots for citizens to connect (Figure 13).

- Photovoltaic applications: PV panels mounted on the top of the kiosks can provide green energy for bus stops and provide LED inductive lighting systems at night [6].

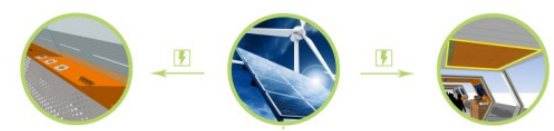

Supply $5 \mathrm{G}$ base station Solar photovoltaic panel Supply energy-saving lamp lighting

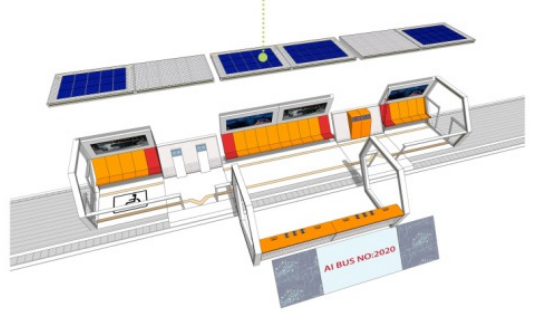

Figure 13. Analysis diagram of intelligence.

- Environmental monitoring: real-time detection of urban road environment, air quality, urban temperature, etc., and aggregation of real-time urban data.

- Shared platform: With the help of a third-party platform, it provides functions such as charging mobile phones, debiting from different platforms, and vending machines.

- Visualization: LCD high-definition screen, playing city cultural propaganda video, displaying city image, advertising and other video information.

- Voice station-reporting function: timely broadcasting the bus arrival and departure time and updating the time for passengers in real time (Figure 14).
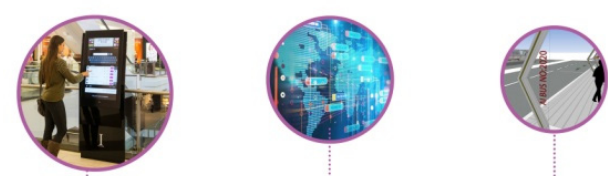

Guide the touch screen Vehicle position guide screen Electronic station board

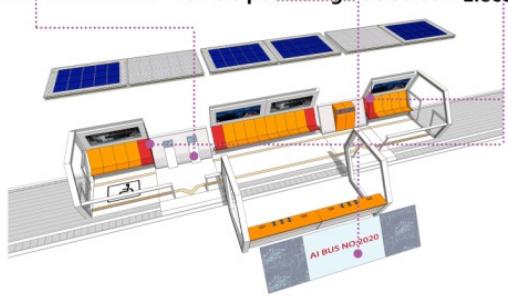

Figure 14. Analysis diagram of intelligence.

- Humanization design: Zhengzhou, as a northern city, it is difficult to sit for a long time in winter, so the waiting seats will be equipped with a seat heating function.

- Smart city: LCD touch screen, that can show the realtime operation status of public transportation and information about stops, routes and transfers, as well as searching for ticketing information of surrounding scenic spots and life service information such as weather forecast and map navigation.

\section{Summary}

This paper expounds the design strategy of future "intelligent transportation" based on the sustainable development of the intelligent city through the thinking of the design of Zhengzhou driverless bus stops.

(1) by creating manned (open) - shared (transitional space) - unmanned (semi-enclosed space) space, adding transitional space and unmanned mode to the existing platform, it can adapt to the changes now and in the future, that is, meet the functional requirements of manned bus stations at the present and unmanned bus stations in the future. To avoid dismantling manned bus stations in an allround way but upgrade and optimize, it can save a lot of social resources, investment and time cost, and echo the urban sustainable development strategy in intelligent transportation.

(2) Modular design is an important application method of the sustainable concept in the field of architectural design. Unify the image of the city through modularization, and increase bus stop services through diversification, so as to enhance the city. The application of modular design strategy in the field of architectural design can not only save architectural resources effectively, but also maintain the sustainable vitality of architectural space. However, modular construction can continue to develop and flourish only if it meets the actual functional requirements, conforms to the corresponding social and cultural forms and adapts to the means of material construction.

\section{References}

1. General Rules for Design of Civil Buildings, GB50352-2019, (2019)

2. Code for Fire Protection Design of Buildings, GB50016-2014, (2018)

3. Abe, Introducing autonomous buses and taxis: Quantifying the potential benefits in Japanese transportation systems. Transportation research part A-policy and practice, 126, 94-113 (2019)

4. A. Chehri, H.T. Mouftah, Autonomous vehicles in the sustainable cities, the beginning of a green adventure. Transportation Research Record, 37-46 (2016)

5. X.X. Dong, M. Di Scenna, E. Guerra, Transit user perceptions of driverless buses. Transportation, 46, 35-50 (2019)

6. L.M. Eugenia, A. Alonso, The Driverless Bus: An Analysis of Public Perceptions and Acceptability. Sustainability, 11, 4986 (2019) 